\title{
Research on the detection technology of structure intensity parameters of Rigid Optional Site
}

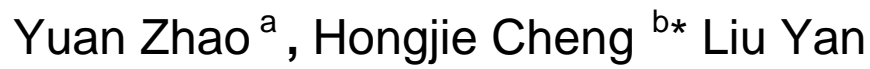 \\ Xi'an Research Inst.of Hi-tech, Xi'an, 710025, China \\ azy44630@163.com, 'bchenghongjie181170@163.com
}

Keywords: Unsupported random launching, bearing capacity, single factor analysis.

\begin{abstract}
The feasibility analysis which selects the spreading cement site of service area of expressway as unsupported random launching site is studied in this paper. The structure stress in cement slab is calculated based on load characteristic of launch vehicle, and the key influence factors of bearing capacity of rigid pavement is discussed. Analysis result shows, to flexural-tensile stress of pavement bottom, the thickness of rigid pavement has significant influence comparing with other factors, and the flexural-tensile stress of pavement bottom will increase with the increment of pavement modular, while decrease with the increment of equivalent modular of top surface of soil base. To verify the accuracy of the built influence regularity of stress change in rigid cement slab, a 3D finite element model of optional site is created, which used to certify the vary regularity achieved by theoretical analysis. Simulation and comparison result shows the influence regularity to load stress of the thickness of rigid pavement, and pavement modular generated by theoretical analysis coincides with 3D finite element model.
\end{abstract}

\section{Introduction}

To enlarge the optional range of launching site, the scheme is presented that the broad rigid pavement of expressway service area is chosen as optional site of missile random launching. But, as a kind of brittle material, the selected cement concrete site of expressway service area shows lower capability of adapting to inhomogeneous deformation of roadbed. When bearing the load to ground, it has much higher requirement of non-deformability of roadbed. In current design method of cement concrete pavement, the non-deformability of roadbed is mainly attributed by static modulus of resilience $^{[1]}$. Under the influence of small diameter of plate-bearing, big differential between applied load and effective bearing load of roadbed, the test result has much difference relative to reality ${ }^{[2]}$. When analyzing the stress of cement concrete pavement, the pavement structure is often simplified to elastic anchor plate system or elastic multi-layer system.

Directed toward the evaluation problem of bearing capacity of service area of expressway, the loaded concrete slab stress model which generated by external load is established while the load stress computing theory of Westergaard is applied based on the mechanical property of optional site constructed materials, which can offer technical support for selecting and expending missile unsupported launching site.

\section{Theoretical analyzing of launching site load stress}

Different to common cement concrete pavement, when computing structure stress, to the broad site of expressway service area, the given method of design specification can not be applied for the less load action frequency. And the method which applying equivalent fatigue damage principle which converting the action order number of different axle type and load level to standard axle load can not adopted $^{[3]}$. Thus, the load stress computation theory which established by Westergaard is adopted to compute the structure stress although the applied theory will underrating the bearing capacity of foundation, and the influence degree is much finite to judge the variation regularity of parameter sensitivity of ultimate bearing capacity. 
When the external load acts on the middle of concrete slab, the stress in concrete slab can be expressed as:

$$
\sigma_{c}=\frac{3(1+\mu) P}{2 \pi h^{2}}\left(\ln \frac{r}{l}+0.6159\right)
$$

Where $P$ - the load to ground; $h$ - - thickness of concrete slab; $r$ - -radius of relative rigidity; $\mu-$ Poisson ratio; $l-$ - c constant related to contact ground radius of external load.

While exists

$$
l= \begin{cases}R & R \geq 1.742 h \\ \sqrt{1.6 R^{2}+h^{2}}-0.675 h & R<1.742 h\end{cases}
$$

The radius of relative rigidity of concrete slab can be expressed as

$$
r=0.537 h \cdot \sqrt[3]{\frac{E_{c}}{E_{t}}}
$$

Where $E_{c}$ - flexural-tensile elastic modular of facing concrete; $E_{t}$ _- equivalent resilience modulus of top surface of base which can be achieved by the equation (4) ${ }^{[4]}$.

$$
\left\{\begin{array}{l}
E_{t}=a h_{x}^{b} E_{0}\left(\frac{E_{x}}{E_{0}}\right)^{\frac{1}{3}} \\
E_{x}=\frac{h_{1}^{2} E_{1}+h_{2}^{2} E_{2}}{h_{1}^{2}+h_{2}^{2}} \\
h_{x}=\left(\frac{12 D_{x}}{E_{x}}\right)^{\frac{1}{3}} \\
D_{x}=\frac{h_{1}^{3} E_{1}+h_{2}^{3} E_{2}}{12}+\frac{\left(h_{1}+h_{2}\right)^{2}}{4}\left(\frac{1}{E_{1} h_{1}}+\frac{1}{E_{2} h_{2}}\right)^{-1} \\
a=6.22\left[1-1.51\left(\frac{E_{x}}{E_{0}}\right)^{-0.45}\right], \quad b=1-1.44\left(\frac{E_{x}}{E_{0}}\right)^{-0.55}
\end{array}\right.
$$

Where $E_{0}$ - - resilience modulus of top surface of roadbed; $E_{x}$ —-equivalent resilience modulus of base and sub-base; $E_{1} 、 E_{2}$ - - resilience modulus of base and sub-base; $h_{x}$ - - equivalent thickness of base and sub-base; $D_{x}$ ——equivalent bending rigidity of base and sub-base; $h_{1} 、 h_{2}$ thickness of base and sub-base; $a 、 b$ - regression coefficient related to $E_{x} / E_{0}$.

\section{Influencing factor analysis of load stress}

Fracture is main structural damage mode of concrete pavement. the reason is that the generated stress of pavement layer under the combined action of load and environmental factors exceeds the intensity of concrete. With the repeat action of these factors, fatigue fracture will appear in concrete pavement layer ${ }^{[5]}$.

Equation (1) to equation (4) shows that load stress of rigid pavement structure has significant relationship with the thickness of concrete slab, resilience modulus and thickness of base layer and sub-base course, flexural-tensile elastic modulus and so on. For the limited influence capability of sub-base course, the variation of sub-base course parameter is neglected when analyzing pavement structure ultimate bearing capacity.

\section{Influence generated by thickness of concrete slab}

To analyze the influence of concrete slab thickness to load stress accurately and roundly, associating with pavement structure material basic parameter which shown in table 1 . 
Table 1 Model structure material parameter

\begin{tabular}{ccccc}
\hline \multirow{2}{*}{ Structure level } & Material type & thickness/ & Elastic modular/MPa & Poisson ratio \\
\hline pavement layer & cement concrete & 0.22 & 32000 & 0.16 \\
base layer & cement steady granular & 0.18 & 1200 & 0.20 \\
cushion course & cement steady soil & 0.16 & 600 & 0.25 \\
soil matrix & Clay soil & 5.00 & 30 & 0.35 \\
\hline
\end{tabular}

The load stress in pavement slab is computed under different thickness of pavement layer according to the launching flow, and the computation result is illustrated in Fig.1.

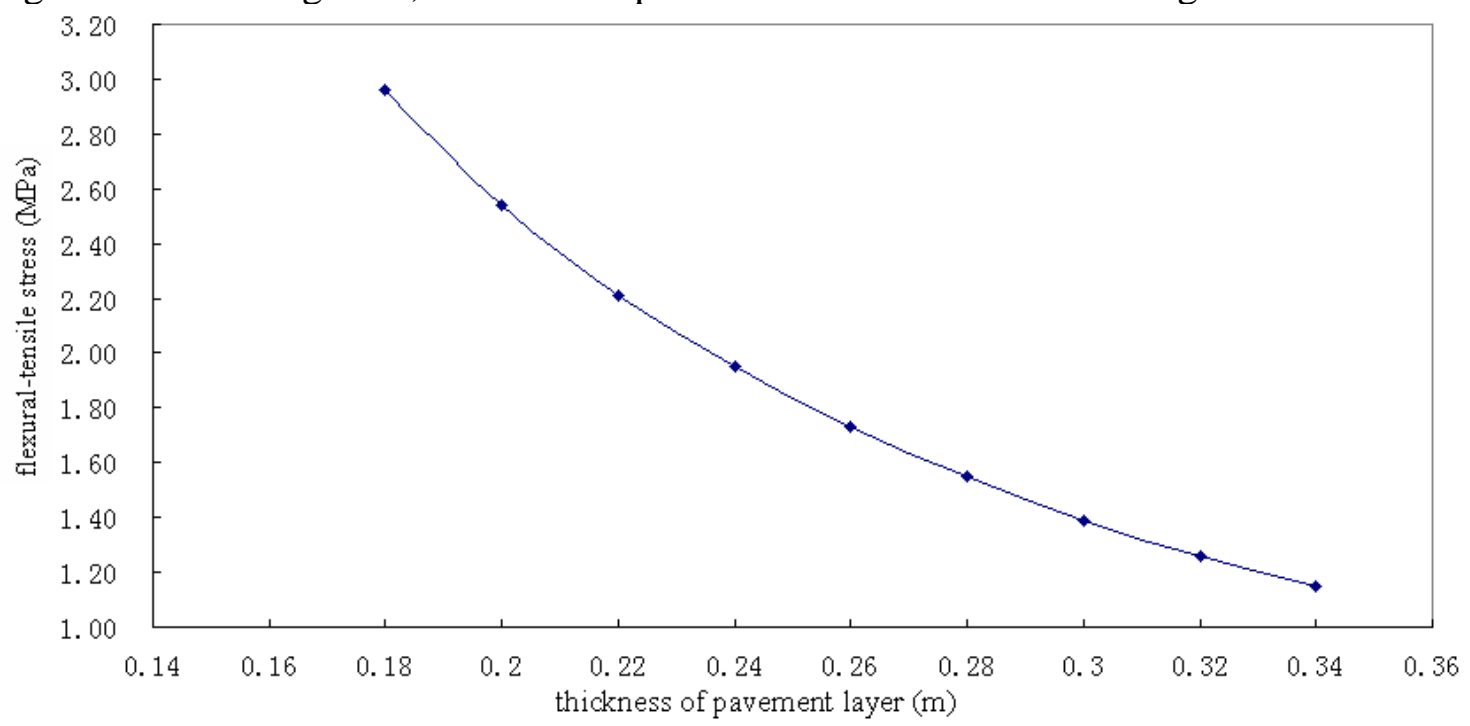

Fig.1 Influence generated by thickness of pavement layer

From Fig.1 can we see that maximum flexural-tensile stress in bottom of pavement slab will decrease obviously with the increase of cement concrete pavement layer thickness. The stress will decrease from 2.2094MPa to $1.2597 \mathrm{MPa}$ when the pavement layer thickness increase from $0.22 \mathrm{~m}$ to $0.32 \mathrm{~m}$, and the down-amplitude is about 42 percent. Thus, the variation of pavement layer thickness shows significant influence to flexural-tensile stress, and the thickness of pavement layer must be taken into account when field detecting the influence factors of ultimate bearing capacity.

\section{Influence generated by flexural-tensile elastic modulus of concrete pavement layer}

Flexural-tensile elastic modulus is main parameter which applied to attribute the rigid pavement property, and the load action has significant influence to flexural-tensile stress of bottom of rigid pavement slab. To analyze the influence effect, let the flexural-tensile elastic modulus change from $22000 \mathrm{MPa}$ to $36000 \mathrm{MPa}$ while other parameter keep original value yields regular shown in Fig.2. 


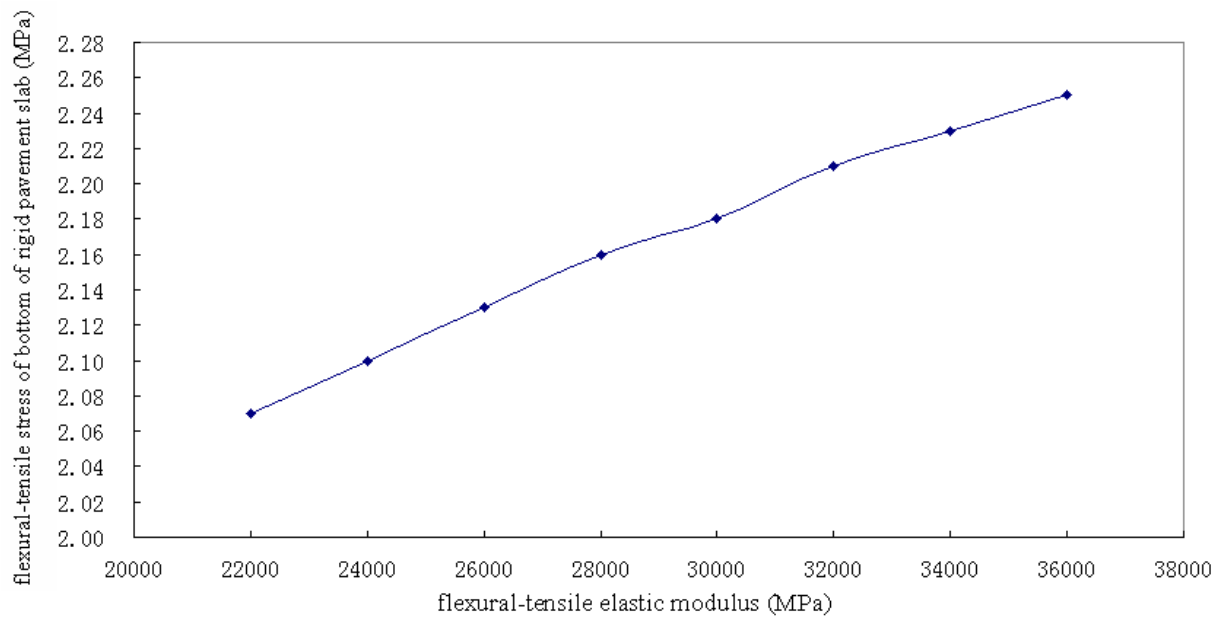

Fig.2 Influence generated by pavement slab flexural-tensile elastic modulus

Fig. 2 shows the regularity that flexural-tensile stress will increase with the increment of elastic modulus of pavement slab. The maximum flexural-tensile stress will increase from $2.0698 \mathrm{MPa}$ to 2.2493MPa when elastic modulus increase from 22000MPa to $36000 \mathrm{MPa}$, and the increase amplitude is about 8 percent. The elastic modulus of pavement slab increases $2000 \mathrm{MPa}$ in interval, the flexural-tensile stress will increase 1 percent probably.

\section{Influence generated by equivalent resilience modulus of top surface of base layer}

To achieve preferable service performance of pavement in integrality, the elastic modulus of base layer must keep in a reason range. When analyzing the influence to load stress of concrete pavement which generated by variation of equivalent resilience modulus of top surface of base layer, let the modulus value change from $150 \mathrm{MPa}$ to $300 \mathrm{MPa}$ while other parameter keep original value yields regular shown in Fig.3.

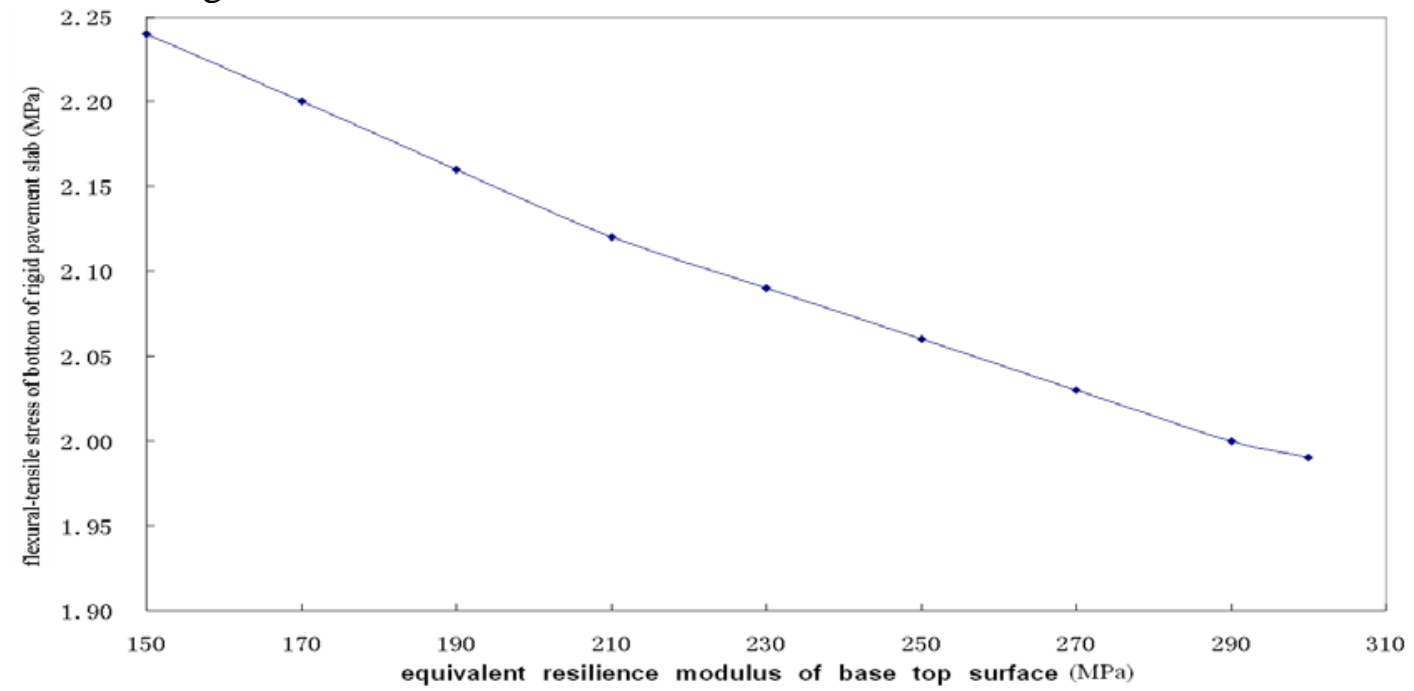

Fig.3 Influence generated by equivalent resilience modulus of base top surface

Fig. 3 shows the regularity that load stress of bottom of concrete slab will decrease with the increment of equivalent resilience modulus of top surface of base layer. The load stress will decrease from 2.2437MPa to $1.9911 \mathrm{MPa}$ when the equivalent resilience modulus increase from $150 \mathrm{MPa}$ to $300 \mathrm{MPa}$, the down-amplitude is about 11 percent. The equivalent resilience modulus increases 20 $\mathrm{MPa}$ in interval, the flexural-tensile stress will decrease 2 percent probably.

\section{D finite element computation and analysis}

To verify the influence regularity of main influence factors of bearing capacity and influence trend to bearing capacity generated by parameter variation, a 3D finite element analysis model is 
established. Under the same circular evenly distributed load effect, the final result is yielded and shown in Fig.4.

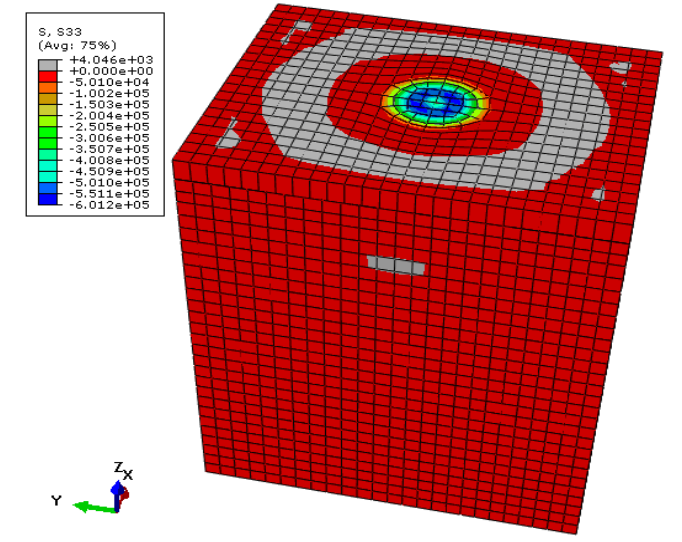

Fig.4 the stress computation result of load effect in launching flow

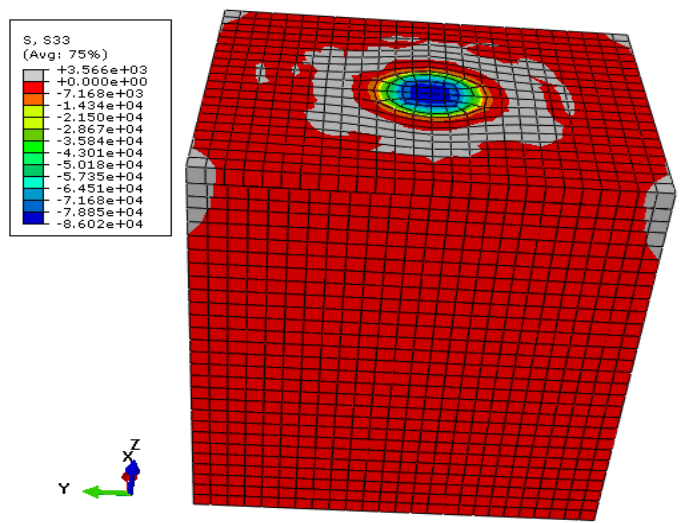

Fig.5 the stress computation result of load effect while the thickness increasing

To analyze the influence of load stress generated by the thickness of concrete pavement layer, the thickness is raised to $0.28 \mathrm{~m}$, while other parameters keep the raw value shown in table 1 , which yields the result illustrated in Fig.5.

From the finite element computation result, the conclusion can be drawn that the maximum flexural-tensile stress of pavement slab bottom will decrease obviously with the increment of cement concrete pavement slab thickness. The change regular coincides with theoretical computation result preferably.

To further analyze the influence regularity generated by flexural-tensile elastic modulus, the elastic modulus of pavement layer increases from $32000 \mathrm{MPa}$ to $36000 \mathrm{MPa}$ while other parameters keep raw values achieves the result which shown in Fig.6.

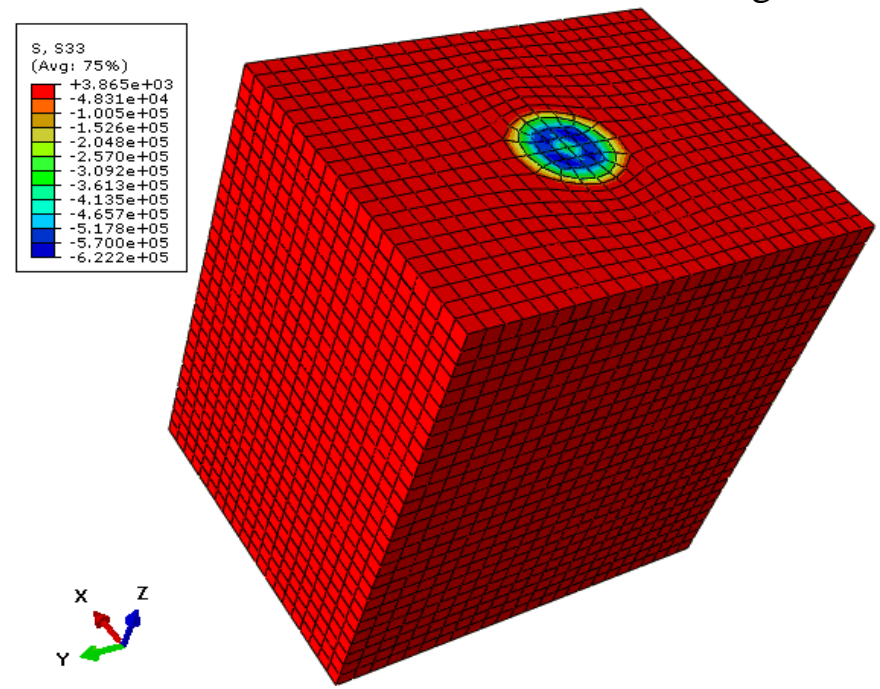

Fig.6 the stress computation result of load effect while elastic modulus increasing

From the computation result, through applying 3D finite element method, the gained mechanical response change regularity of flexural-tensile stress generated by elastic modulus shows the same trend with theoretical analysis conclusion.

\section{Conclusion}

In this paper, a mechanical model of expressway service area is established, and the main factors which influence the bearing capacity of rigid pavement and influence regularity are analyzed systematically. Through contrasting and analyzing, the possibility of the method which applying finite element modeling technique to analyze the bearing capacity of launching site.

The achieved conclusion as follows: The cement site designed according to current specification, whose bearing capacity of pavement shows low sensitivity to parameter verification of base layer, 
and the influence provided by verification of elastic modulus of pavement slab is quite smaller than the verification of pavement slab thickness. Through contrasting and analyzing, the possibility of the method which applying service area of expressway as optional launching site has been proved effectively. Finally, the reliability gist has also been provided to evaluate and detect the optional site of expressway service area.

\section{References}

[1] Profession Standard P R. China. Design specification of highway cement concrete pavement (JTG D40-2003) [S]. Beijing: People Traffic Press, 2003.

[2] Feng Rui. Calculation method of subgrade rebound deflection [J]. Measurement \& Supervision, 2010, Vol(7): 111-114.

[3] Deng Xue-jun, Huang Xiao-ming. Principle and Method of Pavement Design [M]. Beijing: People Traffic Press, 2001.

[4] Zhang Wei, Zong Lan. Analysis and Verification of the Load Stress Based on ANSYS in the Concrete Pavement of High Crack-resistance [J]. Jiangsu Construction, 2010, Vol(4): 49-50, 75.

[5] Jiang Ming. Analysis on Fatigue Fracture of Old Cement Concrete Pavement Asphalt Overlay [J]. Value Engineering, 2010(30): 208-209. 